\title{
वैश्विक महामारी और अथर्ववेदीय चिकित्सा पद्धति
}

\section{डॉ. किरण आर्या}

उद्देश्य - 'वैश्विक महामारी और अथर्ववेदीय चिकित्सा पद्धति' इस लेख का उद्देश्य जनमानस में प्राचीनतम खोयी हुई परम्परा को आधुनिक युग में पुनः जीवन्त करना है। उद्देश्य स्पष्ट है कि जो प्राचीन हवन, योग, प्राणायाम, सात्तिक आहार आदि वर्तमान वैज्ञानिक युग में भी परम आवश्यक हैं तथा इस नित्यकर्म (हवन, प्राणायाम आदि)से आधुनिक वैज्ञानिक भी अब पूर्णतया सहमत हैं। वेद एवं आयुर्वेद चिकित्सा पद्धति आज भी उसी तरह ही प्रासंगिक है जिस तरह अर्वाचीन में प्रयुक्त होने वाली एलोपैथी चिकित्सा पद्धति। अतः स्पष्ट है कि समूचे विश्व में उस परम्परा का लोहा पुनः माना जिस परम्परा को हम मन से, कर्म से भूल चुके थे। अतः ऋषि दयानन्द का कथन तथा उनकी अभिलाषा पूर्णतया दिग्दर्शित हो रही है कि 'वेदों की ओर लौटो।'

प्रत्येक प्राणी जो संसार में उत्पन्न हुआ है अन्त में उसकी मृत्यु अवश्य है परन्तु पूर्ण आयु के भोगे बिना न किसी को मरना चाहिए और न कोई मरना चाहता है। जीवन की आशा रखते हुए पूर्ण आयु का उपयोग और उपभोग करना अत्यन्त आवश्यक और स्वाभाविक है। मनुष्य की पूर्ण आयु सौ वर्ष और इससे भी अधिक हो सकती है। स्वयं अथर्ववेद में कहा है- "जीवेम शरद: शतम्" 'भूयसी शरदः शतम्' (अथर्व- 19/67/2,8)इसलिये प्रमादवश अपनी पूर्ण आयु को नष्ट करना बड़ा अपराध व कर्त्तव्यहीनता है। हाँ, जीवन में अयुक्त आहार-विहार द्वारा रोगों से आक्रान्त हो जाना, यह सम्भव है। जैसा कि वर्तमान समय में अकर्मात् फैली वैश्विक महामारी पूरे विश्व को तहस नहस किये हुये है। ऐसा प्रतीत होता है कि परमात्मा अपने रौद्र रूप में है। वर्तमान काल में फैले इस कोरोना महामारी की कोई स्थायी चिकित्सा नहीं दिख रही है। किन्तु इसके निवारण के जो साम्भाविक उपाय बताये जा रहे हैं उसके मूल में हमारी भारतीय संस्कृति की छाया स्पष्ट ही दृष्टिगोचर है। स्वच्छता, पवित्रता, शाकाहार, हवन, प्राणायाम, युक्ताहारविहार आदि उपायों को अपनाना ही इसका समाधान है ऐसा सभी मानने को विवश हो रहे हैं। चीन से फैला यह कोरोना वायरस हमें हमारे पुरातन संस्कृति को अपनाने पर मजबूर कर रहा है। अपि च इस वायरस के जो लक्षण हैं- सर्दी, खांसी, बुखार, श्वासबन्द, इस सबका भी घरेलु उपचारतुलसी, अदरक, गिलोय, मुलैठी, सोंठ आदि का आयुर्वेदिक काढ़ा भी हमें अपने चरक, सुश्रुत, आयुर्वेद, अथर्ववेदीय चिकित्सा शास्त्र की ओर पलटकर देखने का अवसर प्रदान कर रहा है और हम अब यह निश्चित अनुभव कर रहे हैं कि "यदिहास्ति तदन्यत्र यन्नेहास्ति न तत् क्वचित्" जो भारत के पास नहीं है वह कहीं नहीं है और जो भारत के पास है वही सबको मानना होगा तभी हम सुरक्षित हैं।

अथर्ववेद में वह सारी चिकित्सा पद्धति हमें प्राप्त होती है जो कि हमारे स्वास्थ्य के लिये सर्वथा उपयोगी है। स्वस्थ व्यक्ति रोगी न हो और रोगी स्वस्थ हो जाये यही आयुर्वेद व अथर्ववेदीय चिकित्सा पद्धति का प्रयोजन है। "शरीरमाद्यं खलु धर्मसाधनम्" शरीर ही धर्म-साध्य का प्रथम साधन है अतः शरीर को स्वस्थ रखना जीवन का ध्येय होना चाहिए और इसके लिये प्रथम पुरुषार्थ 'स्वस्थ-वृत्त' है। इसी को युक्त आहार-विहार कहते हैं। अथर्ववेद के 'यदनाद्यं सर्वमविषं कृणोमि' मन्त्रांश में प्रार्थना की गई है कि हम वस्त्र, पात्र, स्थान, विहार के उपकरण आदि सभी को विषरहित कीटाणुरहित करते हैं। सुश्रुत में विषदोष का अधिष्ठान केवल खान-पान को ही नहीं कहा अपितु विहार के उपकरण भी दूषित हो जाते हैं। ऐसा लिखा है- अन्नपाने दन्तकाष्ठे तथाभ्यंगेऽलेखने। 
उत्सादने कषाये च परिषेके नुलेपने। स्रक्षु वस्त्रेषु शय्यासु कवचाभरणेषु च। पादुका-पादपीठेषु पृष्ठेषु गजवाजिनाम्। विषजुष्टेषु चान्येषु नस्यधूमाझ्जनादिषु। लक्षणानि प्रवक्ष्यामि चिकित्साभप्यनन्तरम्1अर्थात् खान-पान तथा दन्तध ावन, स्नान के जल, कंघे, उबटन (पाउडर आदि) कषाय (द्रव उबटन), चन्दन आदि लेपन, माला, वस्त्र, शय्या (बिस्तर, पलंग) धातुओं के बने पहनने योग्य शरीररक्षक, उपरिवस्त्र, आभूषण, खड़ाऊं, आसन, इत्र, धूप, अंजन आदि विषयुक्त (कीटाणुयुक्त) हो जाने का वर्णन है। कौटलीय अर्थ शास्त्र में वायु के भी विषदूषित हो जाने का वर्णन है।

उपर्युक्त प्रमाण द्वारा स्पष्ट है कि कुछ विषाणु ऐसे होते हैं जो प्रत्येक पदार्थ को विषयुक्त, कीटाणुयुक्त कर देते हैं और उन पदार्थों के स्पर्श से यह विषाणु मानव को रोगी बना देते हैं। इस संसार में कोई भी कीटाणु तथा विषाणु बिना वायु के जीवित नहीं रह सकते। कुछ कीटाणुओं और विषाणुओं के चलायमान का साधन भी वायु ही होती है। हवा में सम्मिलित होकर वे स्थान से दूसरे स्थान की यात्रा तय करते है, अन्तर ये है कि धरती पर उत्पन्न उन जैसे जीवों का जीवन कम होता है किन्तु कुछ दीर्घजीवी होते हैं पहले से ही अस्वस्थ शरीर में यदि वे प्रवेश कर गये तो उसे अपना घर बना लेते हैं और मानवीय शरीर की सारी प्रतिरोधक क्षमताओं को खत्म करके स्वयं क्षमताओं से पुष्ट हो जाते हैं किन्तु यदि मनुष्य की काया स्वस्थ है तो उन जीवाणुओं विषाणुओं को या तो अपना अन्त करना होता है या उस शरीर को छोड़कर वायु के माध्यम से अन्य स्थान को चला जाना होता है। इसलिए आधुनिक भारतीय वैज्ञानिकों ने घोषित कि पूर्ण स्वस्थ शरीर में जल्दी इस तरह के कीटाणुओं विषाणुओं का असर नहीं होता सन्दर्भित इस बात को सारे वैदिक ग्रन्थों ने पुष्ट किया और सर्वप्रथम शरीर को स्वस्थ रखने की बात कही है। शरीर को स्वस्थ रखने के लिए शुद्ध वायु, शुद्ध जल प्रयोग की बात कही है क्योंकि आहार चाहे जितना पौष्टिक हो किन्तु जलवायु यदि दूषित है तो आहार अपनी पुष्टता को देने में अक्षम हो जाता है।

संसार में मानवों तथा मानवेतर प्राणियों में अनेक महामारियों की समस्या आती रही है, आती रहेगी क्योंकि जहाँ शरीरधारी प्राणी हैं उसके साथ यत् किंचिंत् रोगों की श्रृंखला अवश्य होती है उनके निवारणार्थ संस्कृतग्रन्थों में, वेदों में, आयुर्वेदों में इन रोगों पर विचार विमर्श बहुतायत से प्राप्त होता है किन्तु वैज्ञानिक युग की चिकित्सा पद्धति को आसान समझकर इसे स्वीकार करने में हम अपनी महत्ता समझते हैं। इन महामारियों से बचाव के उपाय के विषय में पूर्व से ही चरकसंहिता, सुश्रुत आदि में लिखा गयाआयुर्वेदिक इलाज, जिसे आज वैज्ञानिक प्रयोग के लिये जनता को प्रेरित कर रहे हैं, वह हमारे ग्रन्थों में बहुत पहले से ही बता दिया गया है। यहाँ हम अथर्ववेदीय उस चिकित्सा पद्धति को प्रस्तुत कर रहे हैं जो वर्तमान में फैली महामारी के निवारणार्थ सफल हो सकती है।

अथर्ववेद की चिकित्सा में सभी रोगों के निदान के सम्बन्ध में विचार नहीं किया गया है किन्तु जो प्रधान रोग हैं उन्हीं के निदान पर प्रकाश डाला गया है क्योंकि अन्य रोगों के निदान भी उन प्रधान रोगों के निदान से सम्भव है। ज्वर समस्त रोगों में प्रधान रोग है ऐसा 'चरक' में कहा गया है-

इह तु ज्वर एवादौ विकारनामुपदिश्यते तत्प्रथमत्वाच्छरीराणाम् (चरक, निदान स्थान 1,31) ज्वरयति शरीराणि इति ज्वर: ...। स रोगाधिपतिर्नाना तिर्यग्योनिषु च बहुविधै: शब्देरभिधीयते सर्वप्राणभूतश्च सज्वरा एवं जायन्ते सज्वरा एव म्रियन्ते... सर्वप्राणभृतां ज्वर एवान्ते प्राणानादत्ते। 
अर्थात् रोगों में सर्वप्रथम रोग ज्वर है क्योंकि प्राणियों के अन्दर प्रथम ज्वर ही होता है वही सब रोगों का अधिपति है। नाना प्रकार की तिर्यक् योनियों में भी यह रोग पाया जाता है। यह रोग प्राणियों को बहुत सन्ताप पहुंचाता है। ज्वर से प्राणी मर जाते हैं। प्राणधारियों को अन्त में यह ज्वर ही ग्रस्त करता है। ज्वर: देहेन्द्रियमनस्तापकर:3 ज्वर रोग देह, इन्द्रियों और मन को पीड़ादेने वाला होता है। ज्वर से पेट के रोग होते हैं उसके जीर्ण होने पर यकृतऔर प्लीहा के रोग हो जाते हैं तथा यक्ष्म ज्वर में परिवर्तित हो जाने पर हृदय और गले के रोग हो जाते हैं। दूसरा प्रधान रोग है मानसिक रोग, और मानसिक रोग से उत्पन्न उन्माद रोग। तीसरा प्रधान रोग है बाह्य कारणों से होने वाला प्रधान रोग आघात या क्षत। ये तीन रोग समस्त रोगों में प्रधान हैं। अत एव इनके निदान पर सर्वप्रथम विचार किया गया है। वर्तमान समय में फैले रोग में भी ज्वर ही प्रधान है अतः सर्वप्रथम ज्वर की ही जांच की जा रही है। तथा सर्दी, खांसी, गले का अवरोध यह सब वात पित्त कफ इन ह तातुओं की विषमता के कारण होता है क्योंकि ज्वर आदि समस्त रोगों का प्रथम तथा सामान्य कारण धातुवैषम्य अर्थात् वात पित्त कफ धातुओं की विषमता अयोग्य स्थिति ही है जैसा कि अथर्ववेद में कहा है-

\section{यो अभ्रजा वातजा यश्च शुष्मो वनस्पतीन्। सचताँ पर्वतांश्च।।}

अर्थात्य: $=$ जो रोग, वातजा: $=$ वात से उत्पन्न, जिसका वात कारण है। शुष्य: $=$ पित्त से उत्पन्न, जिसका पित्त कारण है। यश्च = और जो, अभ्रजा: $=$ कफ से उत्पन्न, जिसका श्लेष्मा अर्थात् कफ कारण है। उस ऐसे रोग से रोगी को मुक्त करना चाहिए वह ऐसे कि उक्त रोगी, वनस्पतीन् = वनस्पतियों को, च = और पर्वतान् $=$ पर्वतीय स्थानों में उत्पन्न होने वाली औषधियों (गिलोय, पुनर्नवा, सोमलता) का, सचताम् = सेवन करे। इस मन्त्र में वनस्पतियों के सेवन की बात कही है। आयुर्वेदिक औषधियां ही वनस्पतियां है, जो वनों में पर्वतों में प्राय: स्वतः ही उत्पन्न होती रहती हैं। मूच्छित लक्ष्मण को सचेत करने के लिए हनुमान जी संजीवनी बूटी लेकर आये थे जो कि पर्वत पर ही उत्पन्न थी। आगे अथर्ववेद में ज्वर के कारण की चर्चा करते हुए बताया गया है-

\section{यत् त्वं शीतथो रूर: सह कासा वेपयः।}

\section{भीमास्ते तक्मन् हेतयस्ताभि: स्म परिवृड्डि्धि नः।।}

अर्थात् तक्मन् $=$ हे ज्वर! यत् = कि, त्वम् = तुम, शीतः = शीत पहुँचाने वाला, कफ प्रधान श्लैष्मिक, अथो $=$ और, रूर: $=$ अग्निरूप, तापकारी $=$ पित्तप्रधान पैत्तिक तथा कासा सह वेपय: $=$ खांसी के साथ कम्पाने वाला वात प्रधान (वातिक) हो, ते $=$ तेरे, हेतय: $=$ शस्त्र समान घातक आक्रमण या वेग, भीमा: = भयंकर हैं, ताभि: $=$ उनसे, न: = हमें परिवृड्डि्ध स्म = मुक्त करो। यहाँ स्पष्ट कहा गया है कि यह वात पित्त कफ की अनियमितता से हुआ ज्वर का आक्रमण भयंकर घातक होता है। वात पित्त कफ की अनियमितता अयुक्ताहारविहार के कारण ही होता है। ज्वर आने के अन्य भी गौण कारण अथर्ववेद की अन्य ऋचाओं में वर्णित है वहाँ कहा गया है कि

\section{ओको अस्य मूजवन्त ओको अस्य महावृषाः। यावज्जातस्तक्मंस्तावानस्मि वहिनेषु न्योचरः।।}

अर्थात् इस ज्वर की उत्पत्ति स्थान (मूजवन्तः) घास वाले जंगल हैं तथा (महावृषा:) बहुत वर्षा वाले जल से युक्त प्रदेश है तथा जहाँ सूर्य की किरणें तथा वायु सम्यक् न पहुँच पाती हों, ऐसे गन्दे स्थानों में भी ज्वर की 
उत्पत्ति होती है। जिसको मलेरिया नामक ज्वर कहा जाता है- मल का एरिया अर्थात् गन्दगी के स्थान पर होने वाला। घास के घना होने या बरसाती जल के सड़ने से मच्छर आदि कृच्छ्र विषजन्तुओं की अधिकता हो जाती है पुनः उनके काटने से शरीर में विष प्रवेश कर जाता है वह सीधा मनुष्यों में ज्वर का कारण बन जाता है। इसी प्रकार नगर में भी ऐसे स्थान में रहने से ज्वर हो जाता है जहां सूर्य किरणों का तथा वायु का प्रवेश न हो, वह स्थान सीलन वाला होने के कारण विषकृमियों का आवास बन जाता है और वायु दूषित होने से ज्वर का घर बन जाता है। ऐसे घरों में ज्वर एक बार घुस जाता है तो उसका निकलना असम्भव हो जाता है इसलिए घरों में शुद्धि, स्वच्छता, हवन होना, सूर्य प्रकाश का आना तथा वायु संचार होना चाहिए।

अथर्ववेद में उपाय भेद से चिकित्सा कई प्रकार की दी है। सर्वप्रथम उपाय है आश्वासन। आशा, विश्वास और सन्तोष का नाम आश्वासन है। रोगी को सबसे पहले रोग दूर हो जाने का आश्वासन देना चाहिए यदि कोई वैद्य अथवा डॉक्टर आश्वासन चिकित्सा में सफल है तो वह रोगी को स्वस्थ कर सकता है तथा वही रोगी स्वस्थ हो सकता है जिसके मन में आश्वासन से यह निश्चय हो जाये कि मेरा रोग दूर हो जायेगा अथवा मैं बच जाऊंगा। इसीलिये इस उपयोगी आश्वासन चिकित्सा का वर्णन वेद में किया है। यथा-

\section{सोऽरिष्ट न मरिष्यसि न मरिष्यसि मा बिभेः।}

\section{न वै तत्र म्रियन्ते नो यन्त्यधमं तमः।।}

अर्थात् वैद्य रोगी से कहता है कि हे रोगी! तुम रोग से पीड़ित होने वाले नहीं हो तुम्हारा रोग शीघ्र दूर होने वाला है। तुम्हारा रोग साध्य है असाध्य नहीं। तुम चिन्ता बिल्कुल मत करो, तुम अवश्य स्वस्थ हो जाओगे, न मरिष्यसि न मरिष्यसि = तुम इस रोग से मरोगे नहीं, मेरी चिकित्सा से कोई नहीं मरता, मरना तो दूर, रोग का कष्ट भी शरीर में देर तक नहीं ठहरता, अतः विश्वास रखो मैं तुम्हें शीघ्र स्वस्थ कर दूंगा।

अधिक घबराने वाले रोगी को आश्वासन देते हुए अथर्ववेद की ऋचा कहती है-

\section{यदि क्षितायुर्यदि वा परेतो यदि मृत्योरन्तिकं नीत एव। तमाहरामि निऋर्धरूपस्थादस्पार्षमेनं शतशारदाय।।}

अर्थात् हे रोगी! तुम्हारा रोग निश्चित ठीक होगा घबराने की आवश्यकता नहीं। चिकित्सक रोगी से कहता है कि में तो यहां तक कर सकता हूँ कि यदि तुम क्षीण आयु वाले भी क्यों न हो, चाहे मृत्यु के समीप भी क्यों न पहुँच गये हो मैं तुम्हें मृत्यु की गोद से वापस ले आऊंगा और सौ वर्ष तक जीने के योग्य तुम्हें बना दूंगा। इस प्रकार अस्वस्थ व्यक्ति को यदि डॉक्टर आश्वासन देता है तो वह मनसा स्वस्थ होने लगता है 'मन चंगा तो कठौती में गंगा' कहावत प्रसिद्ध है, यदि मन स्वस्थ है तो शरीर को स्वस्थ होने में समय नहीं लगता। इतना ही नहीं, रोगी व्यक्ति को औषधि देते हुए भी आवश्वासन देने का विधान अथर्ववेद में है-

\section{उत् त्वा मृत्योरोषधयः सोमराज्ञीरपीपरन्।}

अर्थात्- हे रोगी! तुम जिन औषधियों का सेवन कर रहे हो अथवा जिन औषधियां को। यह वैद्य तुम्हें दे रहा है, इसमें परम महौषधि सोम जीवनतत्त्व देने वाली महारसायन भी है यह औषधि तुम्हें मृत्यु के पार कर देगी अर्थात् तुम्हें बचा लेगी। 
इस प्रकार आश्वासन देने से रोगी को बहुत लाभ होता है। कुशल वैद्य और डॉक्टर के हाथों में, वाणी में रोग दूर करने की मानो शक्ति आ जाती है। वह परोपकार हित दृष्टि और गम्भीरता से मधुर वचनों में जब रोगी को रोग दूर हो जाने का आवश्वासन देता है तो रोगी बिना औषधि के भी रोगशय्या को छोड़ देता है और वह मन से स्वस्थ होकर शरीर को स्वस्थ करने में सक्षम हो जाता है।

रोगी के समीप परिचारक कैसे हों, और किस प्रकार का वार्तालाप, क्रियाकलाप तथा आचार व्यवहार करें यह भी चिकित्सक को ध्यान देना होता है, जिस सम्बन्ध में अथर्ववेद कहता है-

\section{आवतस्त आवतः परावतस्त आवतः ।}

\section{इहैव भव मानुगा मा पूर्वाननुगा: पितृनसुंबधनामि ते दृढम्।।}

अर्थात् आवतः $=$ समीप के सम्बन्धी जन ते = तुम्हारे (हे रोगी $!$ तुम्हारे), आवतः = समीप हैं तथा परावतः दूर के सम्बन्धी जन भी, ते = तुम्हारे, आवतः समीप हैं अतः इस एव भव = इन्हीं सम्बन्धियों हितैषियों के साथ रहो, मानुगा: = इन्हें छोड़ कहीं जाने का उद्यत न होओ। अपने से पूर्व मृत, पितृन् असुम = बाप दादों का, मानुगा: स्मरण इस समय मत करो, ते असुं दृढं बहनामितुम्हारे प्राणों को दृढ़ता से बांधता हूँ।

इस मन्त्र में कहा गया है कि रोगी के हितैषी सम्बन्धी उसके निकट रहें जिससे उसका मन बहला रहे, और वह रोग का भाव कम करे। दूसरी बात कही गयी कि मृत सम्बन्धियों को स्मरण न करना, क्योंकि रोगी का मृत का स्मरण करना या कराना उसे हानिकारक हो सकता है हृदय को आघात पहुंच सकता है।

अथर्ववेद में होम चिकित्सा पर भी बहुत जोर दिया गया है। होम चिकित्सा अर्थात् हवन। हवन ही ऐसा श्रेष्ठ माध्यम है जिसके द्वारा हम अपने पर्यावरण को शुद्ध कर पाते हैं। वायु के सर्वथा शुद्ध होने से रोग मूलतः समाप्त हो जाते है। वर्तमान में फैले महामारी के लिये भी वैज्ञानिक चिकित्सक हवन के लिए, अग्नि में गूगल, कपूर आदि डालकर धुआं करने के लिए प्रेरित कर रहे हैं जिससे वायु में फैला कीटाणु मृतप्राय हो जाता है और मनुष्य को रोगी नहीं कर पाता।

\section{यं भेषजस्य गुल्गुलो सुरभिर्गन्धो अश्नुते।}

अर्थात् गूगल की गन्ध जिस रोगी को व्यापती है वह रोगी के रोग को ठीक कर देती है... आदि अनेक ऋचायें अथर्ववेद में चिकित्सा सम्बन्धी है जो मानव को स्वस्थ रहने के लिये, रोगों से लड़ने के लिये तथा रोग को मूलतः नष्ट करने के लिए बहुत ही उपयोगी हैं। हमारे वैदिक शास्त्रों में हर समस्या का समाधान है परन्तु हम पाश्चात्य हवा के इतने आदि हो गये हैं कि हमें हमारे शास्त्रों में निहित रहस्य दिखाई ही नहीं देते या हम देखने का प्रयास नहीं करते। सम्प्रति व्याप्त 'कोरोना' नामक महामारी ने हमें पुनः अपने अस्तित्व में लौटने का मार्ग दिखाया है यदि हम अपनी संस्कृति का परिपालन और वैदिक क्रियाओं का अनुपालन करेंगे तो हम हर बीमारी से लड़ सकते हैं। गम्भीर से गम्भीर रोगों को नष्ट कर सकते हैं और गर्व से तथा दृढ़ता से अथर्ववेद के इस मन्त्रांश द्वारा 'यदनाद्यं सर्वमविषं कृणोमि' (मैं प्रत्येक रोग का नाश करता हूँ) अपने अन्दर इस विश्वास को पैदा कर सकते हैं कि हम स्वस्थ रहेंगे और समाज को स्वस्थ रखेंगे।

निष्कर्षः इस प्रकार अथर्ववेद शास्त्र का सूक्ष्मतया अध्ययन करने पर हम इस निष्कर्ष पर पहुँचते हैं कि अथर्ववेद में उल्लिखित चिकित्सा पद्धति के प्रकार भिन्न हो सकते हैं किन्तु परिणाम वही है जो आज का 
चिकित्सक अपने रोगी के प्रति, उसके स्वस्थ शरीर में देखना चाहता है। भारतीय संस्कृति की परम्परा प्रणाम और आशीर्वाद की थी, श्रेष्ठ श्रेष्ठतम से गले मिलने की नहीं, उस परम्परा में आज विकृतियां दिखाई दे रही हैं, कोई भी सामान्य छोटा व्यक्ति बड़े व्यक्ति के गले लगकर अपने स्नेह का जैसे प्रमाण देना चाहता है। दैवीय प्रकोप के उस प्राचीन परम्परा को मानो इस संसार में न चाहते हुये भी पुनः प्रतिष्ठापित करने का कार्य किया है। आशा है यह दूरस्थ प्रणाम और आशीर्वाद की परम्परा दीर्घकाल तक इस संसार में जीवन्त रहे।

\section{सन्दर्भ सूची-}

1. सुश्रुत (कल्पस्थान, अ-1/23-25), व्याख्याकार - डॉ. अम्बिकादत्त शास्त्री, प्रकाशक- चौखम्बा संस्कृत संस्थान, वाराणसी

2. चरक (निदान स्थान 1/31), व्याख्याकार- श्री पं. काशीनाथ शास्त्री, प्रकाशक-चौखम्बा संस्कृत संस्थान, वाराणसी

3. चरक (निदान स्थान $1 / 31$ ), व्याख्याकार- श्री पं. काशीनाथ शास्त्री, प्रकाशक-चौखम्बा संस्कृत संस्थान, वाराणसी

4. अथर्ववेद (1.12.3), व्याख्याकार- प्रो. विश्वनाथ विद्यालंकार, प्रकाशक- रामलाल कपूर ट्रस्ट, सोनीपत

5. अथर्ववेद -5.22 .10 , वही

6. अथर्ववेद - 5.22.5, वही

7. अथर्ववेद - 8.2.24, वही

8. अथर्ववेद - 3.11.2, वही

9. अथर्ववेद - 8.1.17, वही

10. अथर्ववेद - 5.30.1, वही

11. अथर्ववेद - 19.38.1, व्याख्याकार- प्रो. विश्वनाथ विद्यालंकार, प्रकाशक- चौधरी प्रताप सिंह, धर्मार्थ ट्रस्ट, हरियाणा 